\title{
Decorating the surface of Escherichia coli with bacterial lipoproteins: a comparative analysis of different display systems
}

\author{
Sonia Nicchi' ', Maria Giuliani', Fabiola Giusti', Laura Pancotto', Domenico Maione', Isabel Delany',
} Cesira L. Galeotti ${ }^{1}$ and Cecilia Brettoni ${ }^{*}{ }^{*}$ (]

\begin{abstract}
Background: The display of recombinant proteins on cell surfaces has a plethora of applications including vaccine development, screening of peptide libraries, whole-cell biocatalysts and biosensor development for diagnostic, industrial or environmental purposes. In the last decades, a wide variety of surface display systems have been developed for the exposure of recombinant proteins on the surface of Escherichia coli, such as autotransporters and outer membrane proteins.
\end{abstract}

Results: In this study, we assess three approaches for the surface display of a panel of heterologous and homologous mature lipoproteins in E. coli: four from Neisseria meningitidis and four from the host strain that are known to be localised in the inner leaflet of the outer membrane. Constructs were made carrying the sequences coding for eight mature lipoproteins, each fused to the delivery portion of three different systems: the autotransporter adhesin involved in diffuse adherence-I (AIDA-I) from enteropathogenic E. coli, the Lpp'OmpA chimaera and a truncated form of the ice nucleation protein (INP), InaK-NC (N-terminal domain fused with C-terminal one) from Pseudomonas syringae. In contrast to what was observed for the INP constructs, when fused to the AIDA-I or Lpp'OmpA, most of the mature lipoproteins were displayed on the bacterial surface both at 37 and $25^{\circ} \mathrm{C}$ as demonstrated by FACS analysis, confocal and transmission electron microscopy.

Conclusions: To our knowledge this is the first study that compares surface display systems using a number of passenger proteins. We have shown that the experimental conditions, including the choice of the carrier protein and the growth temperature, play an important role in the translocation of mature lipoproteins onto the bacterial surface. Despite all the optimization steps performed with the InaK-NC anchor motif, surface exposure of the passenger proteins used in this study was not achieved. For our experimental conditions, Lpp'OmpA chimaera has proved to be an efficient surface display system for the homologous passenger proteins although cell lysis and phenotype heterogeneity were observed. Finally, AIDA-I was found to be the best surface display system for mature lipoproteins (especially heterologous ones) in the E. coli host strain with no inhibition of growth and only limited phenotype heterogeneity.

Keywords: Surface display systems, Lpp'OmpA chimaera, Ice nucleation protein (InaK-NC), AIDA-I, Escherichia coli, Lipoproteins

*Correspondence: cecilia.x.brettoni@gsk.com

${ }^{1}$ GSK, via Fiorentina 1, 53100 Siena, Italy

Full list of author information is available at the end of the article

Laura Pancotto passed away in November 2019

\section{Background}

Yeast $[1,2]$ mammalian $[3,4]$, insect $[5,6]$ and bacterial cells $[7,8,9]$ have been used to display recombinant proteins on their cell surfaces for variou, cell-surface display applications including vaccine development, screening of

c) The Author(s) 2021. This article is licensed under a Creative Commons Attribution 4.0 International License, which permits use, sharing, adaptation, distribution and reproduction in any medium or format, as long as you give appropriate credit to the original author(s) and the source, provide a link to the Creative Commons licence, and indicate if changes were made. The images or other third party material in this article are included in the article's Creative Commons licence, unless indicated otherwise in a credit line to the material. If material is not included in the article's Creative Commons licence and your intended use is not permitted by statutory regulation or exceeds the permitted use, you will need to obtain permission directly from the copyright holder. To view a copy of this licence, visit http://creativeco mmons.org/licenses/by/4.0/. The Creative Commons Public Domain Dedication waiver (http://creativecommons.org/publicdomain/ zero/1.0/) applies to the data made available in this article, unless otherwise stated in a credit line to the data. 
peptide libraries, whole-cell biocatalysts and biosensor development for diagnostic, industrial or environmental purposes $[10,11]$. Among bacterial host strains, Escherichia coli is the most widely used as it is genetically wellcharacterised and has extraordinary versatility due to its rapid growth and ease of genetic manipulation [12]. Over the past years, autotransporters and outer membrane proteins have been efficiently exploited as carrier proteins for the exposure of recombinant proteins (passenger proteins) on the surface of E. coli [13]. Among them, the adhesin involved in diffuse adherence-I (AIDA-I) from enteropathogenic $E$. coli (EPEC) strains $[14,15,16]$ the Lpp'OmpA chimaera $[17,18,19]$ and the ice nucleation protein (INP) from Pseudomonas syringae [20, 21, 22] have been successfully used as targeting vehicles for localising a great number of prokaryotic and eukaryotic full-length soluble proteins, protein domains or peptides on the surface of $E$. coli [13].

These three carrier proteins exploit different mechanisms of translocation to the bacterial surface. AIDA-I is a monomeric autotransporter belonging to the Type $\mathrm{V}$ secretion system (TVSS) consisting of different functional domains [23]: an N-terminal signal peptide, a passenger domain harbouring biological activity in the extracellular space, a linker domain and a translocator domain which is predicted to form a $\beta$-barrel structure integrated into the outer membrane $(\mathrm{OM})$ where it forms a pore through which the translocation of the passenger domain occurs [24]. Autotransporters were originally thought to be self-sufficient for secretion. However, several lines of evidence now strongly suggest that both the secretion of the passenger domain and the membrane integration of the $\beta$ barrel domain are catalysed by the barrel assembly machinery (BAM) complex and perhaps by an additional complex, named translocation and assembly module or TAM $[25,26]$. It has been proposed that the TAM complex may either boost the activity of the BAM complex (consecutive role or by simultaneous cooperation), or function as a backup translocase activated only under high secretory demand [27]. The AIDAI secretion mechanism can be exploited for the surface exposure of recombinant proteins in E. coli by simply replacing the coding region of the natural passenger domain (N-terminus) with that of the recombinant protein of interest [28].

Lpp'OmpA is a chimaera developed by Georgiou and co-workers consisting of the signal peptide and the first nine residues of Braun's lipoprotein or Lpp (Lpp'), responsible for the targeting to the outer membrane, fused with five of the eight membrane-spanning segments of the OmpA porin (residues 46-159). In this case, the protein of interest is fused at the C-terminus of Lpp'OmpA [29]. Although the exact mechanism of translocation exploited by this chimaera has never been described in detail, we can speculate that it entails a combination of lipoprotein and outer membrane protein translocation mechanisms. After the export to the inner membrane (IM), the cysteine residue of Lpp' undergoes lipid modifications in a sequential process catalysed by three periplasmic enzymes: diacylglyceryl transferase (Lgt), signal peptidase II (LspA) and $\mathrm{N}$-acyltransferase (Lnt) [30]. Subsequently, translocation to the $\mathrm{OM}$ is determined by the identity of the amino acids that follow the conserved cysteine, and this leads to the recognition by the localisation of lipoproteins (Lol) pathway [31, 32]. In addition, the correct insertion of the five membranespanning segments of the OmpA porin may require the action of the BAM complex [33].

The last delivery system analysed is the ice nucleation protein (INP) of Pseudomonas syringae. INP is an outer membrane protein that is found in several plant pathogenic bacteria [34]. In P. syringae, InaK, a member of the INP family, is characterised by the presence of three domains. The $\mathrm{N}$-domain is relatively hydrophobic and seems to be the only domain responsible for the targeting to the cell surface. An exposed central part called central repeated domain (CRD) comprises a series of contiguous repeats that act as a template for ice crystal formation. The C-terminal domain is hydrophilic and exposed to the extracellular environment [35]. INP is attached to the outer cell membrane via a glycosylphosphatidylinositol (GPI) anchor in a manner similar to that observed in eukaryotic cells. In addition, three asparagine residues in the $\mathrm{N}$-terminus and one conserved threonine residue in the $\mathrm{C}$-terminus enable the protein to be coupled to various sugars through $\mathrm{N}$ - and O-glycan linkages [35]. It has been shown that full-length INP and various truncated forms yield stable surface display [13]. The construct used in this work comprises only the $\mathrm{N}$-terminal domain fused to C-terminal domains without CRD (InaK-NC) and allows $\mathrm{C}$-terminal fusion of the protein of interest.

All three delivery systems have been shown to efficiently expose heterologous proteins on the surface of E. coli [13], however, their direct comparison has not been previously reported. For the first time, these three approaches are assessed for the surface exposure of several passenger proteins belonging to the same class, the mature portion of lipoproteins. Full-length lipoproteins constitute a specific class of membrane proteins that have been shown to be potential vaccine candidates as they play key roles in adhesion to host cells, modulation of inflammatory processes and translocation of virulence factors into host cells [36, 37]. In this study, a panel of eight lipoproteins was considered: four from Neisseria meningitidis and four from the host strain that are known to be localised in the inner leaflet of the outer membrane. 
The expression of the resulting thirty-two constructs comprising the eight full-length lipoproteins and their mature portion fused to AIDA-I, Lpp'OmpA and InaK$\mathrm{NC}$ was enabled under the control of the T7 promoter. A number of approaches were used to investigate their localisation on the surface of bacterial cells: FACS analysis, confocal and transmission electron microscopy.

\section{Results}

\section{Delivery systems engineering: AIDA-I, Lpp'OmpA} and InaK-NC

A total of thirty-two constructs comprising the eight fulllength lipoproteins and their mature portions fused to AIDA-I, Lpp'OmpA or InaK-NC were engineered in the pET15b expression plasmid as follows (Fig. 1):
(1) As negative controls, the eight full-length lipoproteins retaining their own signal peptide were cloned in the absence of a carrier delivery system.

(2) Each construct with AIDA-I (1554 bp) as a delivery system consists of: an $\mathrm{N}$-terminal signal peptide, the FLAG tag, the TEV (Tobacco Etch Virus) protease cleavage site, a flexible linker and the AIDAI translocator unit. The sequence of each mature lipoprotein was cloned between the FLAG and the TEV cleavage site.

(3) Each Lpp'OmpA fusion (454 bp) consists of the signal peptide sequence, the first nine residues of Lpp (this region is indicated as Lpp') and residues 46-159 of OmpA comprising five of the eight membrane-spanning segments found in the native

a

1) Negative control: full-length lipoprotein

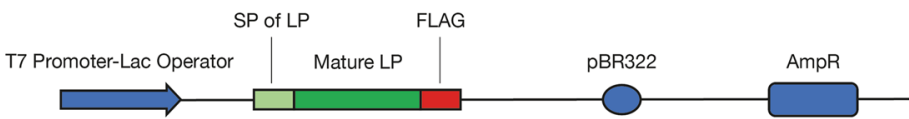

2) AIDA-I (1554 bp) construct

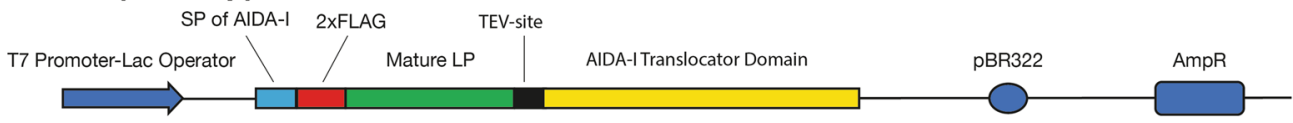

3) Lpp'OmpA (459 bp) construct

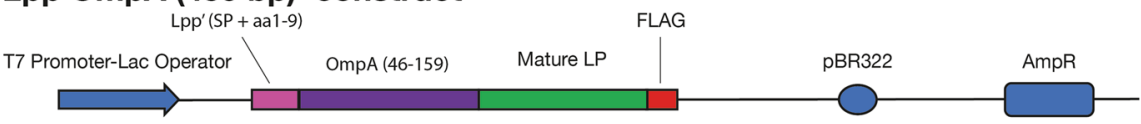

4) INP (inaK, 714 bp) construct

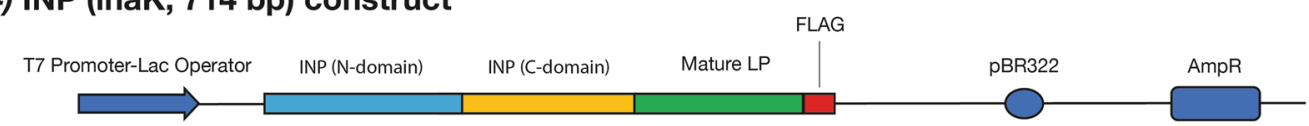

b
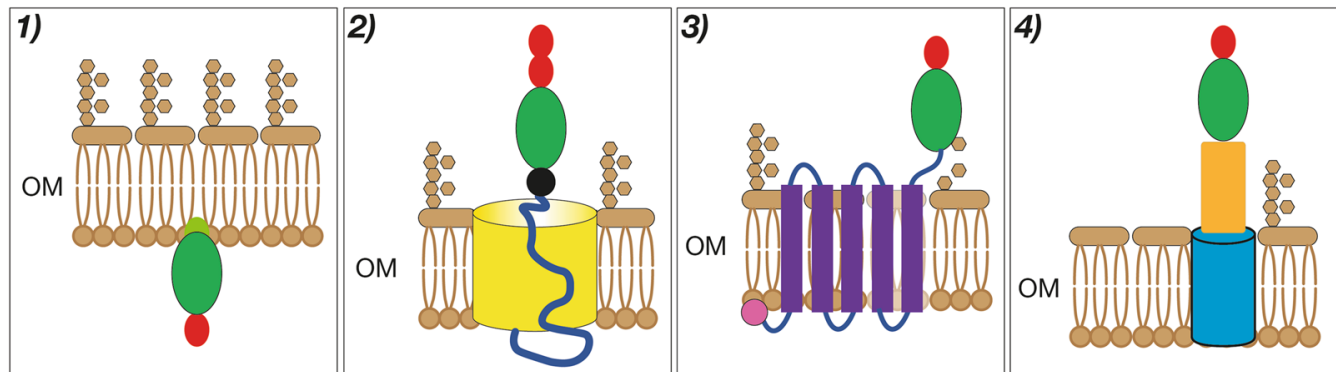

Fig. 1 Schematic representation of the expression and display delivery systems. a Schematic representation of the domains of the constructs expressing recombinant versions of the eight proteins in the four different genetically engineered systems. $\mathbf{b}$ The panel illustrates schematically the display on the OM of each construct including 1) the full-length lipoprotein with its own signal peptide including lipobox lacking a carrier protein system and the mature portion of the lipoprotein fused to 2) AIDA-I, 3) Lpp'OmpA and 4) INP, InaK (N-domain + C-domain). In both panels (a and b), each protein domain is displayed with different colours. SP signal peptide, LP lipoprotein. OM outer membrane 
protein. The FLAG tag is located at the C-terminus of these constructs. The sequence coding for each mature lipoprotein was cloned between the last membrane-spanning segment of OmpA and the FLAG tag.

(4) Each construct of the ice nucleation protein (714 bp) comprises the $\mathrm{N}$-terminal and C-terminal domains of the protein, but lacks all of the central repeating domain (InaK-NC). The FLAG tag is located at the C-terminus of each construct. The sequence of each mature lipoprotein was cloned between the $\mathrm{C}$-terminal domain of INP and the FLAG.

The panel of the heterologous lipoproteins analysed comprises CsgG, MtrC, BamE and a putative lipoprotein from Neisseria meningitidis (NZ98/254) for which there are no data concerning their behaviour in E. coli as a host strain. In addition, four lipoproteins from E.coli K-12 were also analysed: Pal [38], BamE [33], LptE [39] and LolB [40] that are known to be localised in the inner leaflet of the outer membrane. Hence, they represent a useful control to evaluate the efficiency of the three delivery systems. The structure and description of their function are reported in Table 1 . These lipoproteins have a molecular mass ranging from 10 to $40 \mathrm{kDa}$. The percentage of secondary structures present in each lipoprotein was investigated by using the SOPMA software (https://npsa-prabi .ibcp.fr/cgi-bin/npsa_automat.pl?page=/NPSA/npsa_ sopma.html). As can be deduced from Table 1, all the lipoproteins under study have a similar content of alpha helix, beta strand, beta turn and random coils. Hence, only the size and the origin (homologous or heterologous) of the passenger proteins may have an influence on the process of surface translocation.

\section{Surface display of bacterial lipoproteins in E. coli evaluated by FACS analysis}

All thirty-two constructs were introduced into $E$. coli and expression of the proteins was induced under growth conditions at various temperatures. The integrity and size of the different fusion proteins expressed were verified by Western blot and their surface exposure by FACS analysis. The results from Western blot and FACS experiments, from each of the four different genetically engineered systems, are reported in Figs. 2, 3, 4, 5. In order to simplify the interpretation for every given experimental condition, the lipoproteins are shown in two different panels according to their homologous (E. coli) or heterologous ( $N$. meningitidis) origin. The relative percentage of positive cell populations (FITC-A + ) is reported in the figure legends.

Both the neisserial and $E$. coli full-length lipoproteins were well-expressed (Fig. 2, panel A) and as shown by the FACs analysis, in which all of the eight different coloured traces perfectly overlap with the negative control, none of the proteins were surface-exposed at a growth temperature of $37{ }^{\circ} \mathrm{C}$ (Fig. 2, panels $\mathrm{B}$ and $\mathrm{C}$, respectively) nor at $25^{\circ} \mathrm{C}$ (data not shown).

When fused to AIDA-I, all mature lipoprotein domains were well-expressed both at 37 and $25^{\circ} \mathrm{C}$ with the exception of E.coli BamE for which a low molecular weight

Table 1 Description of the passenger proteins expressed in this study

\begin{tabular}{|c|c|c|c|c|c|c|}
\hline Lipoprotein & MW (kDa) & Function & Alpha helix \% & Beta strand \% & Beta turn \% & Random coil \% \\
\hline $\mathrm{Nm}-\mathrm{CsgG}$ & 21.75 & $\begin{array}{l}\text { Involved in curli production, amyloid fibre associ- } \\
\text { ated with biofilm formation, host cell adhesion } \\
\text { and invasion }\end{array}$ & 44.39 & 18.39 & 4.48 & 32.74 \\
\hline Nm-MtrC & 40.33 & $\begin{array}{l}\text { Belongs to the } m \text { tr gene complex, encodes an } \\
\text { efflux pump system responsible for Cationic } \\
\text { Antimicrobial Peptide Resistance }\end{array}$ & 33.01 & 20.63 & 8.98 & 37.38 \\
\hline Nm-BamE & 12.14 & Homologue to E. coli BamE & 32.8 & 18.4 & 8.8 & 40 \\
\hline Putative Lipoprotein & 11.09 & Hypothetical lipoprotein & 51.22 & 6.5 & 8.94 & 33.33 \\
\hline Ec-Pal & 16.68 & $\begin{array}{l}\text { Belongs to the Tol-Pal system. Plays a role in outer } \\
\text { membrane invagination during cell division } \\
\text { and outer membrane integrity }\end{array}$ & 41.04 & 15.03 & 5.78 & 38.15 \\
\hline Ec-BamE & 9.98 & $\begin{array}{l}\text { Modulates the conformation of BamA (lateral } \\
\text { opening). Key role in the OMP assembly pro- } \\
\text { cess and cell envelope conformation }\end{array}$ & 25.66 & 24.78 & 7.08 & 42.48 \\
\hline Ec-LptE & 18.86 & $\begin{array}{l}\text { Involved in the insertion of LPS into the OM, } \\
\text { facilitating O-antigen translocation. Mostly } \\
\text { nested in the } \beta \text {-barrel lumen of LptD }\end{array}$ & 39.41 & 18.24 & 4.71 & 37.65 \\
\hline Ec-LolB & 21.04 & $\begin{array}{l}\text { Essential outer membrane lipoprotein, accepts } \\
\text { lipoproteins from LolA, mediates the outer } \\
\text { membrane anchoring of lipoproteins }\end{array}$ & 21.26 & 26.09 & 6.28 & 46.38 \\
\hline
\end{tabular}



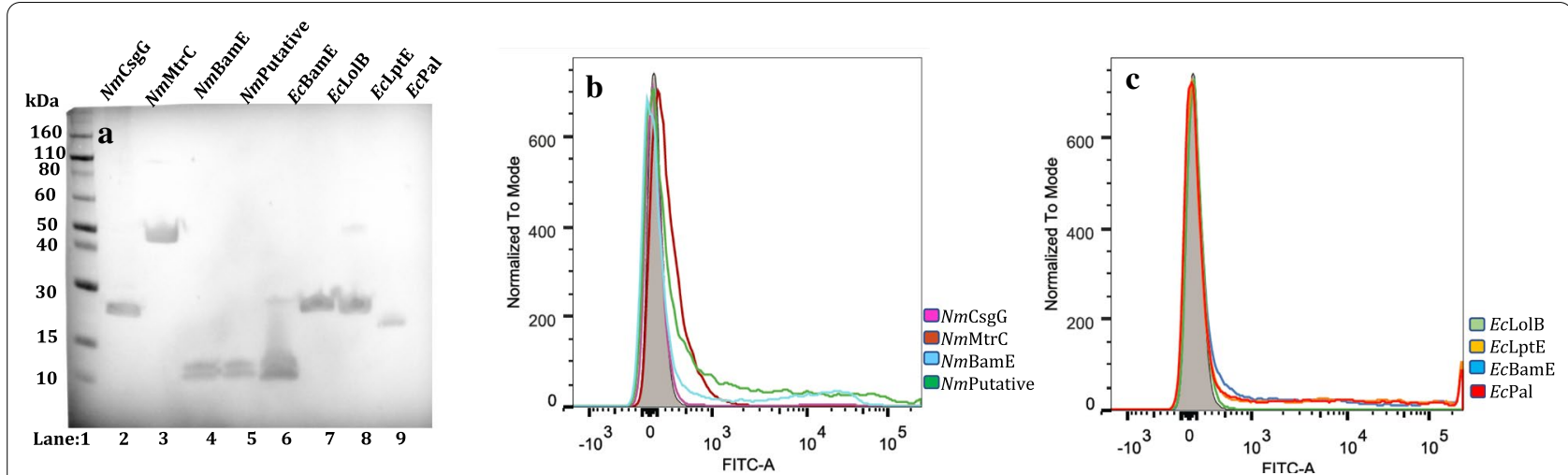

Fig. 2 Expression and surface display of the full-length lipoproteins in E. coli, at $37^{\circ} \mathrm{C}$. a Western blot of whole-cell lysates showing full-length lipoproteins. Lane 1: Marker, Lane 2: NmCsgG, Lane 3: NmMtrC, Lane 4: NmBamE, Lane 5: Nm putative lipoprotein, Lane 6: EcBamE, Lane 7: EcLolB, Lane 8: ECLptE and Lane 9: ECPal. FLAG-tag specific antibodies were used for detection. b, c FACS analysis of E. coli expressing full-length lipoproteins at $37^{\circ} \mathrm{C}$. At $37^{\circ} \mathrm{C}$, E. coli BL21DE3 (pET15b) expressing N. meningitidis lipoproteins: CsgG, MtrC, BamE and a putative lipoprotein (b) and E. coli lipoproteins (c): BamE, LolB, LptE and Pal were incubated with the monoclonal anti-FLAG antibody. The grey areas represent the fluorescence signals obtained with the control (BL21DE3-pET15b Ø). The coloured lines represent the full-length lipoproteins. Panel B (heterologous lipoproteins): Purple: CsgG, Dark Red: MtrC, Light Blue: nmBamE, Dark Green: putative lipoprotein; Panel C (homologous lipoproteins): Dark Blue: BamE, Light Green: LolB, Orange: LptE, Light Red: Pal

band was present. This does not correspond to the form fused with AIDA-I and it may actually represent a cleaved form, suggesting that this protein undergoes proteolysis upon expression (Fig. 3 panels A and B). Three of the four neisserial lipoproteins (CsgG, BamE and putative lipoprotein) were displayed on the bacterial cell surface at both growth temperatures, 37 and $25^{\circ} \mathrm{C}$ (Fig. 3, panels $\mathrm{C}$ and D), with a positive fluorescence signal that was significantly shifted for $N m B a m E$. The lipoprotein with the highest molecular weight, MtrC, was not surface-exposed at either growth temperature (Fig. 3, panels $C$ and D). In the case of the E. coli lipoproteins (Fig. 3, panels E and F), LolB was exposed on the surface of $E$. coli at both temperatures, while the Pal and LptE AIDA-fusions resulted in E. coli showing two populations either expressing or not the specific genes on the bacterial surface. The Pal lipoprotein was not surface exposed at $37^{\circ} \mathrm{C}$, but a significant sub-population gave a positive fluorescent peak at $25{ }^{\circ} \mathrm{C}$. The LptE passenger protein of $E$. coli also showed the same two-population behaviour, but with a clearly lower percentage of cells expressing this protein on the bacterial cell surface compared to Pal at both temperatures. This behaviour may be due to bistability, a condition in which cells with the same genotype separate into two distinct phenotypic populations, for example either expressing or not a specific gene. The occurrence of bacterial subpopulations showing different phenotypic traits within the same culture are known to be often due to the insurgence of epigenetic events occurring in response to stress conditions [41]. In particular, in the present case it may be related to expression levels significantly higher than those characteristic of physiological conditions. This can lead to an overloading of the folding machinery and the trafficking systems, thus preventing the surface translocation or alternatively leading to a misfolded population on the surface causing the lack of the FLAG-tag recognition by the specific antibody [42, 43, 44, 45]. An intriguing aspect that is worth noting is that the percentage of viable and not aggregated bacterial cells accounts for up to $93 \%$ of the population (Additional file 4: Figure S1, panel A), indicating that AIDA-I constructs do not affect viability of the host strain.

All mature lipoprotein domains were expressed when fused to the Lpp'OmpA chimaera both at 37 and $25{ }^{\circ} \mathrm{C}$ (Fig. 4 panels A and B), whereas the surface exposure of the proteins displayed some variability. Bacteria overexpressing these constructs showed a remarkable heterogeneity at $37{ }^{\circ} \mathrm{C}$. This could be deduced by the broad distribution of the fluorescence intensity and by the presence of two distinct positive fluorescence signals (Fig. 4, panels $C$ and $E$ ), indicating populations expressing variable amounts of protein on the surface. Lower heterogeneity was observed when the growth temperature was reduced to $25^{\circ} \mathrm{C}$, which may reflect a better coordination between rate of translation and secretion (Fig. 4, panels $\mathrm{D}$ and $\mathrm{F}$ ). In the case of the neisserial lipoproteins (Fig. 4, panels $C$ and D), Lpp'OmpA-NmBamE was not surface exposed under any experimental conditions. At $37^{\circ} \mathrm{C}$, for Lpp'OmpA fusions with $\mathrm{MtrC}$ and the putative lipoprotein, two populations were detected either expressing or not the specific genes on the bacterial surface, but upon lowering the growth temperature to $25{ }^{\circ} \mathrm{C}$, the negative 

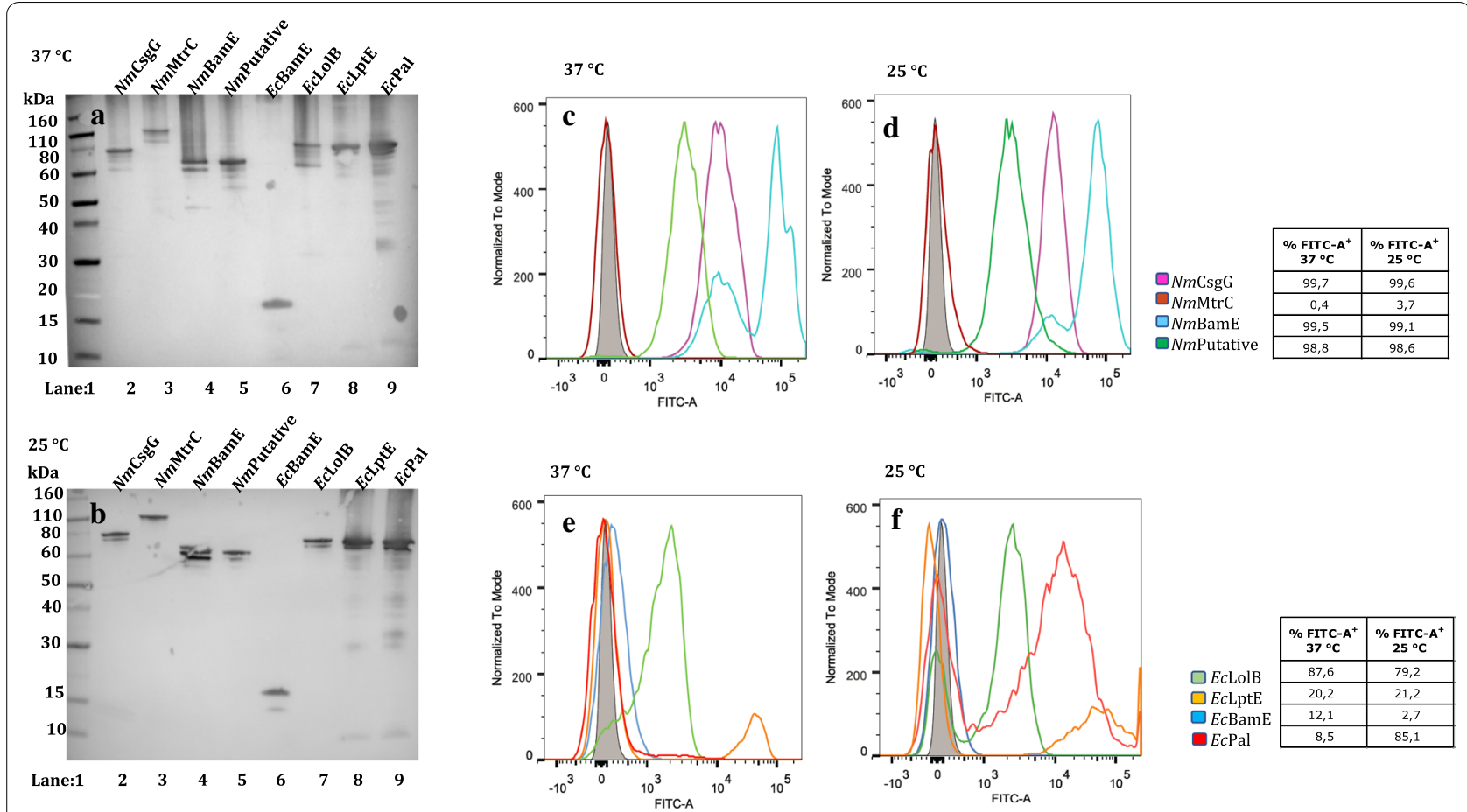

Fig. 3 Expression and surface display of AIDA-I fusion proteins in E. coli, at 37 and $25^{\circ} \mathrm{C}$. Western blot of whole-cell lysates showing AIDA-I fusions proteins. Lane 1: Marker, Lane 2: NmCsgG, Lane 3: NmMtrC, Lane 4: NmBamE, Lane 5: Nm putative lipoprotein, Lane 6: EcBamE, Lane 7: EcLolB, Lane 8: ECLptE and Lane 9: ECPal, at $37^{\circ} \mathrm{C}(\mathbf{a})$ and at $25^{\circ} \mathrm{C}$ (b). FLAG-tag specific antibodies were used for detection. FACS analysis of E. coli BL21DE3 (pET15b) expressing AIDA-I fused to the N. meningitidis lipoproteins: $\mathrm{CsgG}, \mathrm{MtrC}$, BamE and putative lipoprotein at $37^{\circ} \mathrm{C}$ (c) and $25^{\circ} \mathrm{C}(\mathbf{d})$ and the $E$. coli lipoproteins: LolB, LptE, Pal and BamE at $37^{\circ} \mathrm{C}(\mathbf{e})$ and $25^{\circ} \mathrm{C}(\mathbf{f})$ were incubated with monoclonal anti-FLAG antibody. The grey areas represent the fluorescence signals obtained with the control (BL21DE3-pET15b Ø). The coloured lines represent the fused forms of the lipoproteins. Panels $C$ and D (heterologous lipoproteins): Purple: CsgG, Dark Red: MtrC, Light Blue: nmBamE, Dark Green: putative lipoprotein; Panels E and F (homologous lipoproteins): Dark Blue: BamE, Light Green: LolB, Orange: LptE, Light Red: Pal

population completely disappeared either through increased surface expression or decreased misfolding at $25{ }^{\circ} \mathrm{C}$. CsgG fused to the Lpp'OmpA chimaera was not surface exposed at $37^{\circ} \mathrm{C}$ but was at $25^{\circ} \mathrm{C}$, although two populations were still present. By contrast, all the E. coli lipoproteins were surface exposed exhibiting distinct highly positive populations particularly at $25{ }^{\circ} \mathrm{C}$. The main drawback to E. coli overexpressing Lpp'OmpA constructs is that, in most cases, viable and not aggregated bacterial cells represent only $64 \%$ of the population (Additional file 4: Figure S1, panel B).

In the case of the InaK carrier protein, several experimental conditions including, growth temperature, concentration of inducer, time of induction and host strain selection have been investigated. Although the total cell extract revealed that constructs with INP were expressed at high levels, as can be deduced by the presence of clearly visible bands in SDS-PAGE (Additional file 5: Figure S2 panel A), the FACS analysis indicated that none of the lipoproteins were surface-exposed at either 37 or $25{ }^{\circ} \mathrm{C}$ (Additional file 5: Figure S2, panels B-C and D-E, respectively).
One possible explanation for these results is that the chimeras are misfolded. To exclude that the negative fluorescence signals could be due to the lack of FLAG-tag exposure on the bacterial surface, the FACS experiments were repeated at $18{ }^{\circ} \mathrm{C}$ to improve folding however all constructs gave negative FACS results also at this temperature (data not shown). In addition, to confirm that the negative results were not due to lack of exposure of the FLAG-tag on the bacterial surface, we used polyclonal antibodies produced in mouse and raised against the neisserial BamE. Nevertheless, at $25^{\circ} \mathrm{C}$ the $N m B a m E$ lipoprotein was not detectable also using the specific polyclonal antibody (Additional file 6: Figure S3, panel A). Since one important condition that can influence the folding of a chimaera is its level of expression, a different genetic background of the host strain T7express Iq (a BL21 E. coli derivative characterised by a mutation in the LacI gene that results in a reduced level of basal expression) was chosen. Even with this strain at $25^{\circ} \mathrm{C}$ the fluorescence signal was still negative (Additional file 6: Figure S3, panel B). A partially positive FACS signal (24.7\%) was obtained only in the case of the T7express Iq strain 

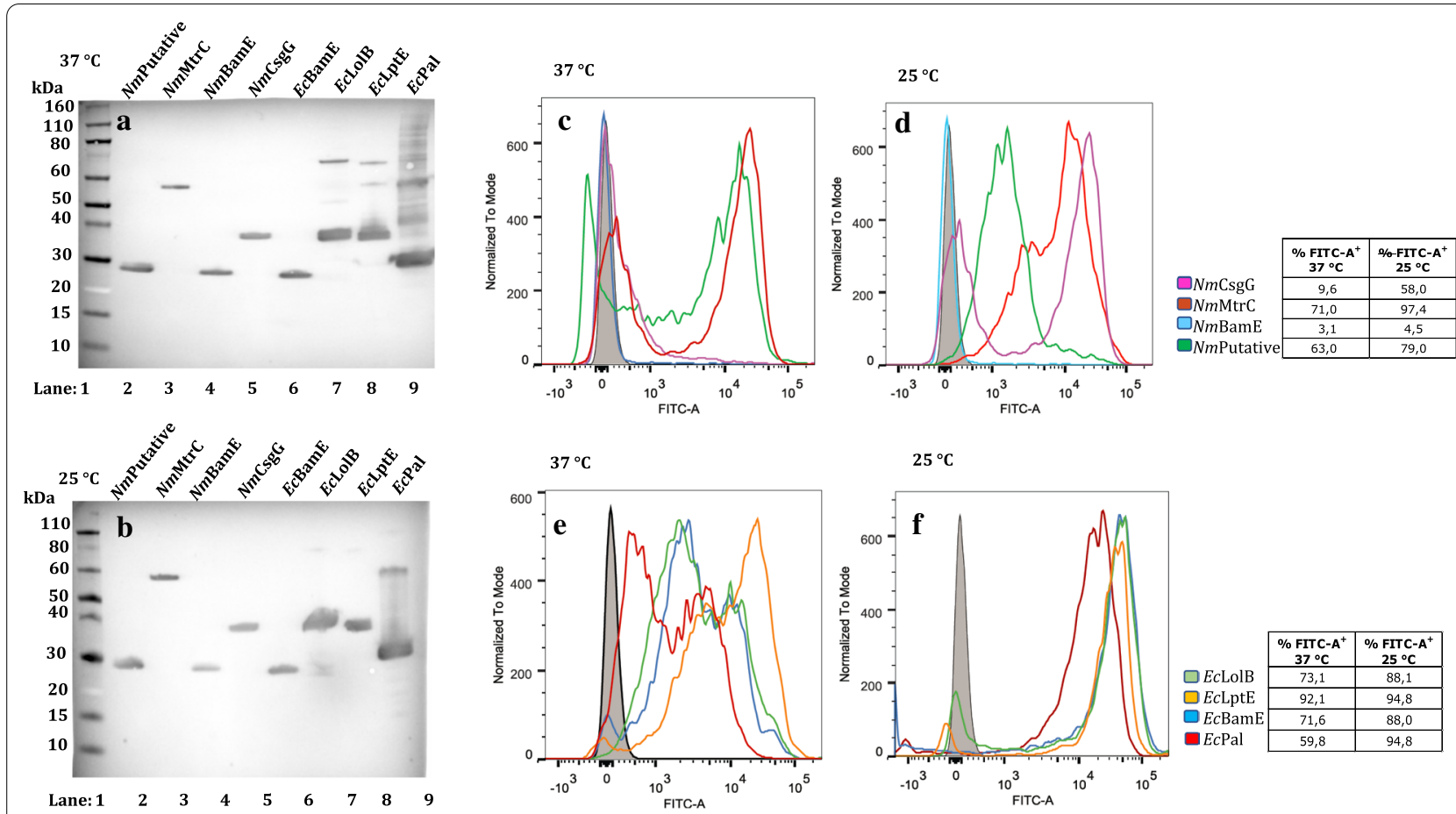

Fig. 4 Expression and surface display of Lpp'OmpA fusion proteins in E. coli, at 37 and $25^{\circ} \mathrm{C}$. Western blot of whole-cell lysates showing Lpp'OmpA fusions proteins. Lane 1: Marker, Lane 2: Nm putative lipoprotein, Lane 3: NmMtrC, Lane 4: NmBamE, Lane 5: NmCsgG, Lane 6: ECBamE, Lane 7: ECLolB, Lane 8: ECLptE and Lane 9: ECPal, at $37^{\circ} \mathrm{C}(\mathbf{a})$ and at $25^{\circ} \mathrm{C}$ (b). FLAG-tag specific antibodies were used for detection. FACS analysis of E. coli BL21DE3 (pET15b) expressing Lpp'OmpA fused the N. meningitidis lipoproteins: CsgG, MtrC, BamE and putative lipoprotein, at $37^{\circ} \mathrm{C}(\mathbf{c})$ and $25^{\circ} \mathrm{C}(\mathbf{d})$ and the E. coli lipoproteins: LolB, LptE, Pal and BamE at $37^{\circ} \mathrm{C}(\mathbf{e})$ and $25^{\circ} \mathrm{C}(\mathbf{f})$ were incubated with monoclonal anti-FLAG antibody. The grey areas represent the fluorescence signals obtained with the control (BL21DE3-pET15b Ø). The coloured lines represent the fused forms of the lipoproteins. Panels C and D (heterologous lipoproteins): Purple: CsgG, Dark Red: MtrC, Light Blue: nmBamE, Dark Green: putative lipoprotein; Panels E and F (homologous lipoproteins): Dark Blue: BamE, Light Green: LolB, Orange: LptE, Light Red: Pal

at $18{ }^{\circ} \mathrm{C}$ (Fig. 5, panel B). In WB analysis, the presence of a band corresponding to the molecular weight of the fusion protein indicated that it is well expressed even at this lower growth temperature (Fig. 5, panel A).

In summary, for our experimental conditions AIDAI and Lpp'OmpA were the best delivery systems for the surface translocation of bacterial mature lipoproteins, with $25^{\circ} \mathrm{C}$ representing the more favourable growth temperature to obtain a homogenous population of bacterial cells expressing the passengers of interest on the bacterial surface. Despite the fact that INP is considered one of the most promising carrier proteins, modulation of many experimental conditions for the InaK-NC construct was not enough to achieve levels of surface exposure comparable to those observed for the other two delivery systems.

\section{Insights into the surface localisation of passenger protein BamE}

In addition to the FACS experiments, the surface localisation of the four different genetically engineered systems of BamE passenger protein was observed by using confocal microscopy and transmission electron microscopy. To this end, as a representative example, we used the anti-BamE polyclonal serum for the INP construct (the only experimental condition that gave us positive signals in the FACS analysis) and the FLAG-antibodies for the others.

As expected, when not fused to a carrier protein, the full-length lipoprotein could not be visualised on the surface of the bacterium as was evident by i) the lack of red fluorescence signals in confocal microscopy (Fig. 6, panel A) and ii) the absence of gold particles in immunogold labelling with TEM (Fig. 6, panel B). When fused to AIDA-I, the neisserial BamE, which gave a positive FACS signal, was detected on the surface of almost all the bacterial cells observed by confocal microscopy (Fig. 6, panel C). The TEM analysis revealed that gold particles were localised on the entire surface of the bacterial cell which showed a well-preserved rod-like shape, thus indicating that the mature protein domain of interest was surfaceexposed (Fig. 6, panel D). Hence, AIDA-I has proved to be an efficient delivery system, able to decorate the whole bacterial cell surface with the antigen expressed at 

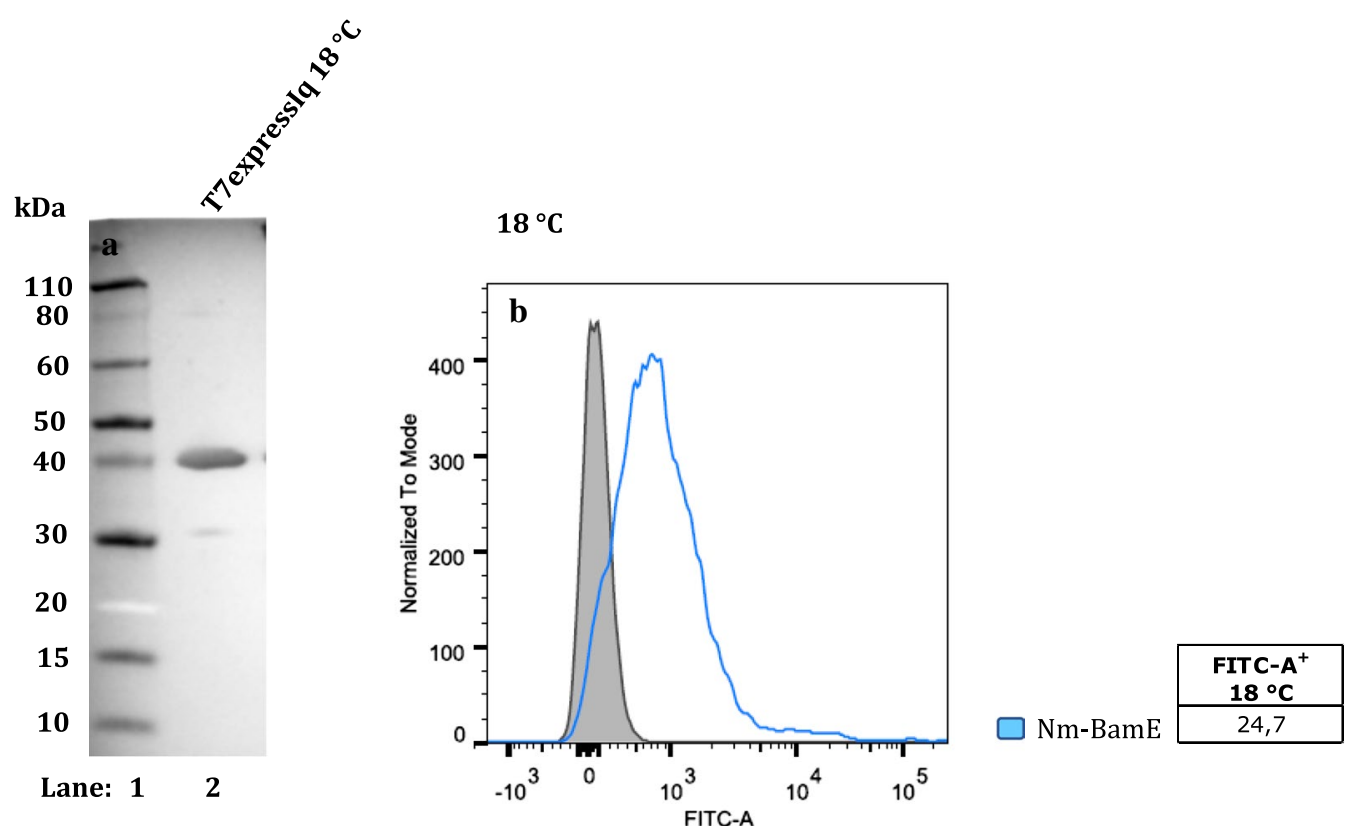

Fig. 5 Expression and surface display of InaK fusion proteins in E. coli, at $18^{\circ} \mathrm{C}$. Western blot of whole-cell lysates showing InaK fusions proteins. Lane 1: Marker; Lane 2:T7Expresslq expressing InaK-NmBamE,at $18^{\circ} \mathrm{C}(\mathbf{a})$. FACS analysis of E. coli T7Expresslq (pET15b) expressing InaK fused the $N$. meningitidis lipoprotein BamE at $18^{\circ} \mathrm{C}(\mathbf{b})$ was incubated with polyclonal anti-NmBamE antibodies. The grey area represents the fluorescence signal obtained with the control (T7Expressla pET15b Ø). The light blue coloured line represents the fused form of the NmBamE lipoprotein

a relatively high level. Confocal microscopy of the bacteria expressing the Ec-BamE lipoprotein fused to the Lpp'OmpA chimaera indicated that BamE was exposed on the surface of almost all bacterial cells (Fig. 6, panel E). The immunogold labelling showed a distribution of the gold particles over nearly the entire surface of the bacterial cell (Fig. 6, panel F), but to a lower extent compared to that observed for the AIDA-I construct. When the neisserial BamE is fused to INP, no signal associated with the protein of interest was observed with confocal microscopy and only very fewgold particles were present on the surface of the bacterial cell (Fig. 6, panels G and H, respectively). It should be noted that bacterial cells overexpressing $N m B a m E$ fused to INP form large aggregates indicating that when the INP construct is overexpressed the bacterial outer membrane undergoes a dramatic change. This is suggested also by the uneven surface observed in the corresponding electron microscope image (Fig. 6, panel H). In addition, the Post-embedding Method using L.R. White Embedding Medium revealed the presence of aggregates of the overexpressed fusion protein even at $18^{\circ} \mathrm{C}$ (Additional file 7: Figure S4).

\section{Discussion}

In this work, AIDA-I, Lpp'OmpA and InaK-NC were selected as they have been previously described as efficient targeting vehicles for the surface localisation of a large number of soluble proteins $[14,15,16,17,20,21]$. Nevertheless, there are few studies describing a direct comparison of the three analysed carrier proteins and they have been limited to only two of the systems, INP and the Lpp'OmpA chimaera. In particular, two research groups engineered E. coli by employing the Lpp'OmpA chimaera and different truncated forms of the ice nucleation protein (InaV) as anchoring motifs for the organophosphorus hydrolase (OPH) enzyme [46, 47]. In contrast to our study, the INP constructs successfully display $\mathrm{OPH}$ on the bacterial surface with good stability and functionality. However, as with our findings, loss of viability was observed in the engineered $E$. coli host strain $[46,47]$. Furthemore, the effectiveness of each approach of surface dysplay has been always analysed by only one or few passenger proteins. Here, AIDA-I, Lpp'OmpA and InaK-NC were assessed in parallel as surface display systems for the exposure on the surface of $E$. coli of the same type of passenger protein: the mature portion of lipoproteins. The panel of investigated passenger proteins comprised eight lipoproteins: four lipoproteins of the host strain and four meningococcal lipoproteins from N. meningitidis strain NZ98/254.

Bacterial lipoproteins are membrane proteins characterised by a conserved lipid-modified cysteine residue at the $\mathrm{N}$-terminus, which allows the mature protein domain to be anchored to a phospholipid in the lipid bilayer after 


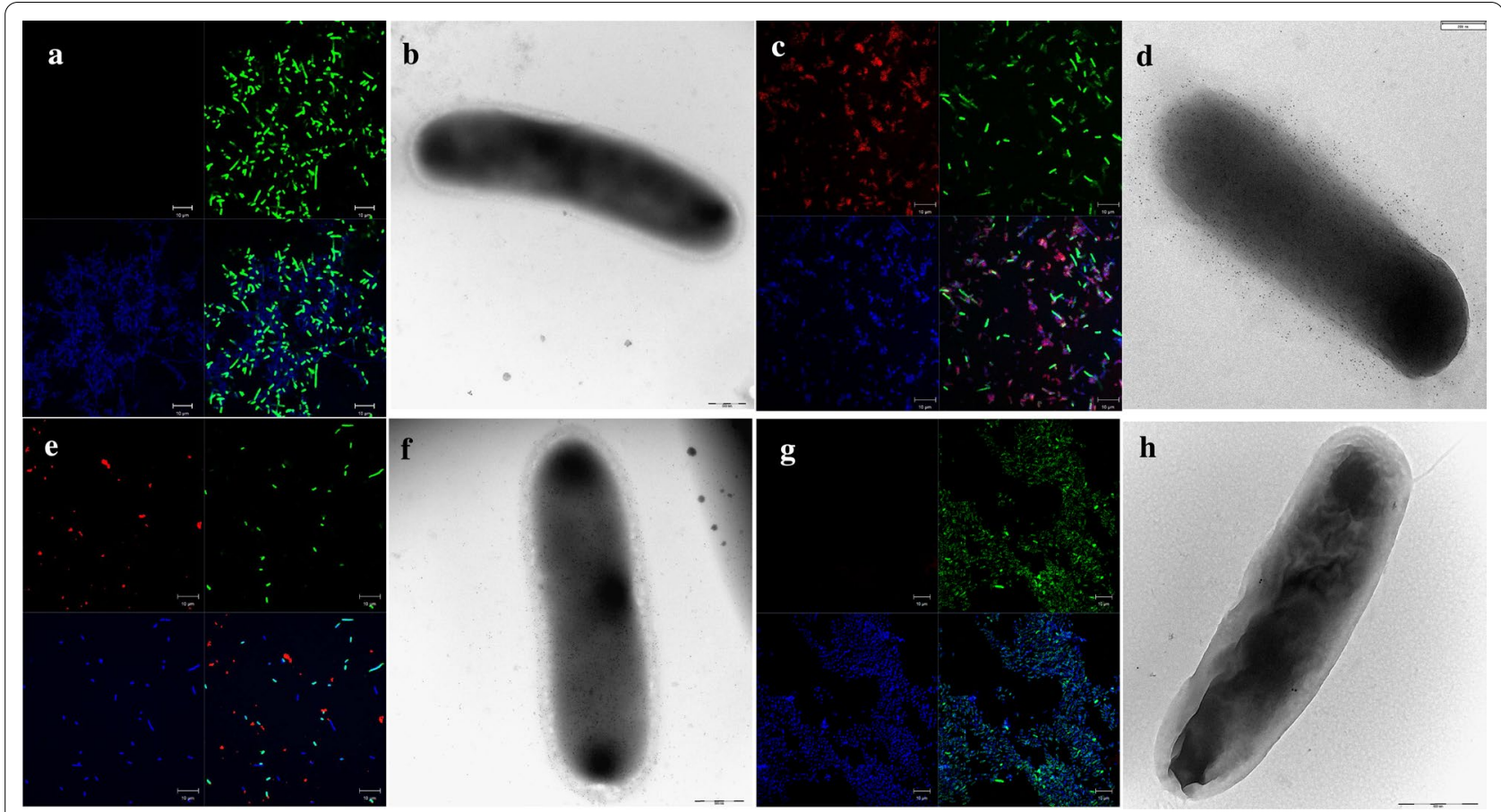

Fig. 6 Confocal and Transmission electron microscopy of BamE expressed in E. coli. E. coli BL21(DE3) expressing the full-length neisserial BamE (a and b), or fused to AIDA-I (c and d), or the E. coli BamE fused to Lpp'OmpA (e and $\mathbf{f}$ ) grown at $25^{\circ} \mathrm{C}$, were incubated first with anti-FLAG antibodies while E. coli T7Expresslq (pET15b) expressing InaK fused to the neisserial BamE grown at $18^{\circ} \mathrm{C}$, was incubated first with polyclonal anti-NmBamE antibodies ( $\mathbf{g}$ and $\mathbf{h}$ ). Subsequently samples were incubated with the secondary anti-mouse immunoglobulin $\mathrm{G}$ (whole molecule) Alexa fluor 568-conjugated. The lipoproteins can be visualized in red, the DNA in blue (DAPI) and the membranes in green (oregon green) (a, $\mathbf{c}, \mathbf{e}$ and $\mathbf{f}$ ). In transmission electron microscopy using immunogold labelling, the same samples were incubated with the secondary anti-mouse immunoglobulin $\mathrm{G}$ conjugated with $5 \mathrm{~nm}$ gold particles $(\mathbf{b}, \mathbf{d}, \mathbf{f}$ and $\mathbf{h}$ )

secretion across the cell membrane and cleavage of the signal peptide. In Gram negatives, when the lipoproteins are not retained in the inner membrane (IM) the conserved Lol system can transport the lipoprotein across the periplasm to the outer membrane (OM) [30, 31, 32]. Most lipoproteins are oriented towards the periplasm in the outer leaflet of the IM or in the inner leaflet of the $\mathrm{OM}$, however, some lipoproteins have been reported to be surface exposed [48]. Homologues of the family of proteins known as surface lipoprotein assembly modulator, SLAM [49], have been identified as translocator proteins for a subset of surface lipoproteins which are substrates specific for the SLAM translocator, originally identified in $N$. meningitidis but present in a number of B-proteobacteria [49]. While Hooda and co-workers demonstrated that the co-expression in E. coli of SLAM1 from $N$. meningitidis with its specific lipoprotein substrate, fHbp, can lead to efficient surface exposure [49], another study reported that in $E$. coli the $N$. meningitidis fHbp spontaneously migrate to the cell surface in a functional conformation [50]. In our study all lipoproteins both of E. coli and N. meningitidis origin, when expressed as lipoproteins and in the absence of a delivery system, were not delivered to the surface of the outer membrane. However, most of the mature lipoprotein domains, when fused to the Lpp'OmpA chimaera or AIDA-I, were properly displayed on the surface of the host.

On the basis of our work, the most critical factors that determined the efficient delivery to the bacterial surface of the mature lipoproteins were found to be a lower induction temperature and/or specificity of the host strain system, which likely had the effect of optimisation of their expression leading to a balance between their rate of translation and secretion. In fact, as has already been reported, when the expression level is too high, the folding machinery and the trafficking systems could become overloaded, thus preventing the expressed protein from being efficiently translocated to the surface $[40,43,51]$. We found this to be especially true for the INP constructs, as demonstrated by the post-embedding TEM image that showed the presence of cytoplasmic aggregates of the overexpressed fusion protein, even at $18{ }^{\circ} \mathrm{C}$ (Additional file 7: Figure S4). It is important to recall that INP is a protein from Pseudomonas syringae, a plant pathogen bacterium only distantly related to $E$. coli. In fact, $P$. syringae is associated with frost damage to crops 
and commonly found living in the wider environment, including water sources and therefore at lower temperature [52]. INP exploits a targeting mechanism still not entirely understood with a rather particular anchoring of the protein based not only on a GPI anchor (a motif quite unique in prokaryotes) but also on $\mathrm{N}$ - and $\mathrm{O}$ - glycosylation [35]. At present, there is no consensus in the literature regarding the effectiveness of INP as a delivery system. It has been reported that the use of the ice nucleation protein for the display of heterologous proteins in $E$. coli depends on the degree of overexpression. At low expression levels, INP is translocated to the outer membranes, whereas in the case of high expression levels the protein is found mainly in inclusion bodies [22, 32, 34]. Nevertheless, it has also been demonstrated that the level of expression is not a critical factor. In particular, the growth temperature has been shown not to have an influence on the surface exposure of passenger proteins such as the green fluorescent protein GFP [35], the carbonic anhydrase from the thermophilic bacterium Sulfurihydrogenibium yellowstonense [20] and the human arginase-1 [21], enzymes that have been successfully exposed at $37^{\circ} \mathrm{C}$. In this work, a low growth temperature $\left(18{ }^{\circ} \mathrm{C}\right)$ and the T7ExpressIq E. coli host strain were used in order to obtain a reduced basal level of expression. Despite all the optimisation attempts with the InaK-NC carrier protein, compared with the AIDA-I and Lpp'OmpA delivery systems, analogous levels of surface exposure of the lipoproteins used in this study were not achieved. Hence, our results have confirmed the concerns related to the effectiveness of INP for surface display applications in E. coli. Therefore, further work is needed to make this approach more generally applicable and reproducible. It would be interesting to evaluate other variants of the INP family, such as InaV and different truncated forms like the $\mathrm{N}$-terminal domain alone or its combination with the C-terminal domain or the central repeating domain (CDR) $[35,54,55]$. An alternative strategy could be the use of different host strains, for example, $P$. syringae, $P$. putida or related species like Moraxella spp [56]. A better understanding of the INP translocation mechanisms is necessary to enable an optimisation of the experimental conditions necessary for this type of construct.

Lpp'OmpA is a good delivery system for surface exposure of homologous lipoproteins. In fact, all the host lipoproteins were surface exposed when fused to the Lpp'OmpA chimaera at all growth temperatures tested. However, cells from the same culture frequently showed two different populations in which a specific gene is either surface-exposed or not. This behaviour may be due to the occurrence of bistability [44, 45]. As possible consequence of this, the percentage of expressing cells showed a significant variation between cultures. In addition, in most cases viable bacteria represented only $64 \%$ of the bacterial population (Additional file 4: Figure $\mathrm{S} 1$, panel $\mathrm{B}$ ). Hence, the difficulties in growing $E$. coli expressing this type of construct limited the use of Lpp'OmpA as a general surface display system. The level of expression had to be tightly regulated in order to avoid growth inhibition and phenotype heterogeneity. These observations are in agreement with previous reports [46, 47].

Within the context of our study, AIDA-I is clearly the most efficient delivery system for surface exposure of heterologous lipoproteins. Three of the four neisserial lipoproteins studied were efficiently exposed on the surface of BL21DE3 E. coli cells at both growth temperatures. In fact, expression of AIDA-I constructs could be easily obtained at 25 or $37{ }^{\circ} \mathrm{C}$ without affecting viability. It is clear from our data that the viability was higher compared with the other three types of construct (93 vs 60-64\%, Additional file 4: Fig. S1). In addition, as demonstrated by confocal and electron microscopy, the passenger protein was expressed at high density on the surface of almost all the bacterial cells. In agreement with our results, this monomeric autotransporter has been previously described as an efficient delivery system for exporting a large number of proteins such as the Salmonella flagellar protein $\mathrm{H}: \mathrm{gm}$, the SE serotype-specific fimbrial protein SefA $[14,15]$ and subsequently their fusion product (H:gmdSefA) [16]. Interestingly, these epitopes appeared to be recognized by HT-29 intestinal cells, as determined by induction of the pro-inflammatory interleukin 8 [16]. Hence, the fusion proteins were in a functional conformation able to induce an immunogenic response.

\section{Conclusions}

This is the first time that three surface display systems have been compared using a number of lipoprotein candidates. It has been demonstrated that the best delivery system to use cannot be defined a priori but has to be assessed case-by-case depending on the experimental conditions and the combination between the carrier and passenger proteins. Despite all the optimization steps performed, the truncated form InaK-NC did not allow an efficient surface exposure of the passenger proteins used in this study. However, we cannot exclude that other variants of the INP family, such as InaV and different truncated forms, may be more successful. In our experimental conditions, the Lpp'OmpA chimaera has proved to be an efficient surface display system for the homologous passenger proteins, but cell lysis and phenotype heterogeneity were observed. AIDA-I has been shown to be the best surface display system for mature lipoproteins (especially heterologous ones) in the $E$. coli host strain without 
growth inhibition and limited phenotype heterogeneity. A crucial aspect that is worthy of further investigation is the evaluation of the conformation and functionality of the constructs after delivery to the surface of $E$. coli. In fact, our study considered the translocation of a good number of mature lipoproteins in order to ascertain the characteristics of the most efficient system in more general terms. By contrary, in an elegant study of the efficiency of the autotransporter AIDA in translocating the enzyme tyrosinase across the bacterial membrane, the most favourable conditions were assessed by using the enzymatic activity of tyrosinase itself to monitor its correct translocation to the cell surface [57]. Therefore, a more thorough functional characterization of the displayed proteins in order to determine their antigenicity will constitute an important aspect of our future work.

\section{Methods}

\section{Bacterial strains and plasmids}

All the cloning steps have been carried out by using the PIPE (Polymerase Incomplete Primer Extension) method, a ligation-independent cloning technique $[58,59]$. The list of the primers used in this work is presented in Additional file 1: Table S1. The first cloning step consisted in the insertion in the pET15b plasmid (Novagen) of the three delivery systems and as a negative control, the full-length genes encoding the analysed lipoproteins. The three display systems AIDA-I, Lpp'OmpA and InaK $(\mathrm{N}+\mathrm{C}$ termini) have been synthesized as dsDNA fragments by GeneArt (Thermo Fisher Scientific, Additional file 2) and, subsequently, amplified by PCR to obtain the corresponding insert to be cloned between the T7 promoter and the $\mathrm{T} 7$ terminator. The newly generated expression plasmids were named pET15b::AIDA-I and pET15b::Lp'OmpA (Additional file 3: Table S2). In all constructs, the FLAG tag was fused to the C-terminus of the recombinant proteins to facilitate protein detection. The second cloning step was to insert the mature portion of each lipoprotein, predicted by the DOLOP software (https://www.mrc-lmb.cam.ac.uk/genomes/ dolop/analysis.shtml), in frame with the delivery systems. The genomic DNA of $N$. meningitidis serogroup B (NZ98/254) and E. coli $\mathrm{K}-12$ were used as templates for amplifying the coding regions of the lipoproteins of interest using Q5 DNA polymerase (Qiagen). All the unpurified PCR products (V-PCR and I-PCR) were used to directly transform chemically competent Mach1 T1R cells (Thermo Scientific). The screening of positive clones was performed by colony PCR and subsequently verified by sequencing. All expression experiments were performed using the BL21(DE3) (Thermo Scientific) and T7 express Iq (New England Biolabs) E. coli strains.

\section{Growth conditions}

Bacteria were inoculated into Luria Bertani (LB) medium at $37^{\circ} \mathrm{C}, 25^{\circ} \mathrm{C}$ or $18{ }^{\circ} \mathrm{C}$, with shaking at $160 \mathrm{rpm}$. When required, ampicillin was added to a final concentration of $100 \mu \mathrm{g} / \mathrm{mL}$. Cultures grown overnight were diluted to give $\mathrm{OD}_{600}=0.1$ and when they reached $\mathrm{OD}_{600}=0.6$ expression of the recombinant fragment was induced with isopropyl $\beta$-d-1-thiogalactopyranoside (IPTG) (Sigma) at a final concentration of $1 \mathrm{mM}$. The time of induction was one/two hours.

\section{Gel electrophoresis and western blot analysis}

A pellet corresponding to $\mathrm{OD}_{600}=1.0$ of each induced bacterial growth was resuspended in $50 \mu \mathrm{l}$ of Cell Lytic (Sigma Aldrich), for $30^{\prime}$ at $37^{\circ} \mathrm{C}$ in a thermomixer with shaking at 600-800 rpm. Total extracts were treated with Loading dye NuPage LDS Sample Buffer 4X (Thermo Scientific) and DTT 10X NuPage Reducing Agent (Thermo Scientific) and denatured at $95{ }^{\circ} \mathrm{C}$ for $5 \mathrm{~min}$. Protein extracts were separated by SDS-PAGE on NuPAGE Novex 4-12\% Bis-Tris Protein Gels in MES 1X (Thermo Scientific). Novex Sharp Pre-Stained Protein Standard (Thermo Scientific) was used as a molecular weight marker. Protein expression was evaluated by Western blot analysis. Protein extracts were transferred onto nitrocellulose membrane using an iBlot Dry Blotting System (Thermo Scientific). Membranes were saturated for $1 \mathrm{~h}$ at room temperature with PBS containing 0.05\% (v/v) Tween 20 (Sigma) and 10\% (w/v) milk BlottingGrade Blocker (Biorad). Membranes were incubated at room temperature for one hour with mouse monoclonal ANTI-FLAG M2 antibody (Sigma), diluted 1:2000 in PBS with 1\% (v/v) Tween 20 (Sigma) and 1\% milk. After being rinsed three times with PBS to remove non-specific binding (10 min each), membranes were incubated for one hour with horseradish peroxidase (HRP)-conjugated anti-mouse IgG antibody (DAkO), diluted (1:2000) in PBS $+1 \%(\mathrm{v} / \mathrm{v})$ Tween $20($ Sigma $)$ and $1 \%(\mathrm{w} / \mathrm{v})$ powdered milk (Sigma). Membranes were then again washed three times with PBS. The Biorad OPTI-4CN substrate kit was used according to the manufacturer's instructions.

\section{Labelling for FACS analysis}

Approximately $10^{8}$ bacteria were collected by centrifugation (10,000 $\mathrm{g}$ for $5 \mathrm{~min})$. Bacteria were fixed for $15 \mathrm{~min}$ at $4{ }^{\circ} \mathrm{C}$ with PBS containing $2 \%(\mathrm{v} / \mathrm{v})$ formaldehyde (Sigma). The fixed bacteria were then suspended in PBS containing $1 \% \mathrm{BSA}(\mathrm{w} / \mathrm{v})$ for $16-24 \mathrm{~h}$ at $4{ }^{\circ} \mathrm{C}$. Inactivated bacteria were centrifuged, resuspended in $100 \mu \mathrm{L}$ of a solution containing monoclonal ANTI-FLAG M2 antibody produced in mouse (or the specific mouse polyclonal sera anti-CsgG and anti-NmBamE) diluted 1:500 in PBS 
containing 1\% BSA and incubated $1 \mathrm{~h}$ at room temperature. Bacteria were washed with $500 \mu \mathrm{L}$ of PBS $+1 \%$ BSA. Each bacterial pellet was then resuspended in $100 \mu \mathrm{L}$ of a secondary rabbit anti-mouse FITC-conjugated immunoglobulin G (whole molecule) (Sigma) diluted 1:250 in PBS $+1 \%$ BSA and incubated for $1 \mathrm{~h}$ in the dark. After a final washing step, the cells were resuspended in 200 $\mu \mathrm{L}$ of PBS. All data were collected using a BD FACS CANTO II (BD Bioscience) by acquiring 10,000 events, and the data analysed using the Flow-Jo software (v.8.6, TreeStar Inc). The combination of the morphologic gate $(\mathrm{x}=$ FSC-A and $\mathrm{y}=$ SSC-A $)$ and single gate $(\mathrm{x}=$ SSC-W and $\mathrm{y}=\mathrm{SSC}-\mathrm{A}$ ) ensures that only viable and single bacterial cells which do not form aggregates are considered.

\section{Labelling for Immunofluorescence analysis}

Strains were grown as described in the section "Growth conditions". Approximately $10^{8}$ bacterial cells were collected by centrifugation $(10,000 \times \mathrm{g}$ for $5 \mathrm{~min})$. Bacteria were washed with $300 \mu \mathrm{L}$ of PBS and fluorescently labelled with Oregon Green 488 Carboxylic Acid, Succinimidyl Ester, 6-isomer (Thermo Scientific) diluted 1:1000 in PBS. Bacteria were washed twice with $300 \mu \mathrm{L}$ of sterile PBS and then resuspended in $100 \mu \mathrm{L}$ of PBS containing $2 \%(\mathrm{v} / \mathrm{v})$ formaldehyde (Sigma). Samples were spotted onto a POLYSINE slide (Menzel-Glaser) and incubated for $10-15 \mathrm{~min}$. Bacteria were washed with $100 \mu \mathrm{L}$ of PBS and then incubated for $40 \mathrm{~min}$ at room temperature with the monoclonal ANTI-FLAG M2 antibody produced in mouse (Sigma) mAb diluted 1:500. Bacteria were washed with $300 \mu \mathrm{L}$ of PBS and incubated for $20-30 \mathrm{~min}$ at RT in the dark with $100 \mu \mathrm{L}$ of PBS containing a secondary rabbit anti-mouse immunoglobulin $\mathrm{G}$ (whole molecule) Alexa fluor 568-conjugated (Thermo Scientific) diluted 1:250. After two washes with PBS, a droplet of a mounting solution containing DAPI was applied. The final step consisted in placing a cover glass on each spot and analysing the samples with a confocal ZEISS LSM700 microscope.

\section{Labelling for transmission electron microscopy}

Strains were grown as previously described. Approximately $2 \times 10^{9}$ bacterial cells were resuspended in $1 \mathrm{~mL}$ of PBS and fixed with $4 \%$ paraformaldehyde. $5 \mu \mathrm{L}$ of each sample were applied to a 200-square mesh nickel grid coated with a thin carbon film. Samples were blocked with PBS $+1 \%$ BSA and then incubated for $1 \mathrm{~h}$ at RT with the primary antibody (diluted 1:250 in the blocking solution). Grids were washed twice and incubated with gold labelled anti-mouse secondary antibodies (diluted 1:40 in $1 \%$ PBS-BSA) for $1 \mathrm{~h}$. Samples were washed in distilled water and observed using TEM FEI Tecnai G2 Spirit operating at $100 \mathrm{kV}$ and equipped with a CCD Olympus
SIS Morada camera (Olympus, Shinjuku, Tokyo, Japan). Images were acquired and processed using the iTemm (OSIS, Olympus, Shinjuku, Tokyo, Japan) software.

To verify the presence of aggregates in T7expressIq (pET15b)INP-NmBamE, post-embedding experiments were performed. The sample was divided into aliquots and fixed $\mathrm{O} / \mathrm{N}$ at $4{ }^{\circ} \mathrm{C}$ in $0.1 \mathrm{M}$ sodium cacodylate buffer containing $2.5 \%$ glutaraldehyde and $2.5 \%$ formaldehyde and then post-fixed in $1 \% \mathrm{OsO}_{4}$. Samples were then dried by the critical point method using $\mathrm{CO}_{2}$ in a Balzers Union CPD 020. The dried samples were embedded in LRWhite resin and stained with uranyl acetate and lead citrate.

\section{Supplementary Information}

The online version contains supplementary material available at https://doi. org/10.1186/s12934-021-01528-z.

Additional file 1: Table S1. List of primers used in this study.

Additional file 2. DNA sequence for the delivery systems used in this study.

Additional file 3: Table S2. List of expression plasmids used in this study.

Additional file 4: Figure S1. FACS analysis of viable and not aggregated bacteria. For each of the four engineered constructs, a representative example was displayed ( $y=S S C-A$ and $x=S S C-W$ ). A) Full-length lipoprotein and its fused forms with B) AIDA-I, C) Lpp'OmpA and D) InaK.

Additional file 5: Figure S2. Expression of InaK fusion proteins in E. coli, at $37^{\circ} \mathrm{C}$ and $25^{\circ} \mathrm{C}$. A) SDS-PAGE of whole-cell lysates showing inaK fusion proteins, at $25^{\circ} \mathrm{C}$. Lane 1: Marker, Lane 2: CsgG, Lane 3: NmBamE, Lane 4: putative lipoprotein, Lane 5: LolB, Lane 6: BamE, Lane 7: LptE, Lane 8: Pal and Lane 9: NmMtrC. FACS analysis of InaK fusion proteins in E. coli, at $37^{\circ} \mathrm{C}$ and $25^{\circ} \mathrm{C}$. E. coli BL21DE3 (pET15b) expressing InaK fused the N. meningitidis lipoproteins: $\mathrm{CsgG}, \mathrm{MtrC}$, BamE and putative lipoprotein at $37^{\circ} \mathrm{C}$ (B) and $25^{\circ} \mathrm{C}$ (D) and the E. coli lipoproteins: LolB, LptE, Pal and BamE at $37^{\circ} \mathrm{C}$ (C) and $25^{\circ} \mathrm{C}$ (E) were incubated with monoclonal anti-FLAG antibody. The grey areas represent the fluorescence signals obtained with the control (BL21DE3-pET15b Ø). The coloured lines represent the fused forms of the lipoproteins. Panels B and D (heterologous lipoproteins): Purple: CsgG, Dark Red: MtrC, Light Blue: nmBamE, Dark Green: putative lipoprotein; Panels C and E (homologous lipoproteins): Dark Blue: BamE, Light Green: LolB, Orange: LptE, Light Red: Pal.

Additional file 6: Figure S3. FACS analysis of NmBamE fused to the InaK delivery system in E. coli, at $25^{\circ} \mathrm{C}$ using the polyclonal anti-NmBamE antibodies. E. coli BL21DE3 and E. coli T7Expressla (pET15b) expressing InaK fused the N. meningitidis lipoprotein BamE at $25^{\circ} \mathrm{C}$ ( $\mathrm{A}$ and $\mathrm{B}$, respectively) were incubated with the polyclonal anti-NmBamE antibodies. The grey areas represent the fluorescence signals obtained with the control (BL21DE3-pET15b Ø or T7Expresslq pET15b Ø, panels A and B, respectively). The Light Blue coloured line represents the fused forms of the NmBamE lipoprotein.

Additional file 7: Figure S4. The Post-embedding Method using L.R. White Embedding Medium was performed to verify the presence of aggregates in T7expresslq (pET15b) InaK-NmBamE.

\section{Abbreviations}

AIDA-I: Adhesin involved in diffuse adherence-l; AT: Autotransporter; Bam: $\beta$-Barrel assembly machinery; BSA: Bovine serum albumin; CRD: Central repeating domains; DAPI: 4',6-Diamidino- 2 phenylindole; EPEC: Enteropathogenic E. coli; FACS: Fluorescence activated cell sorting; FITC: Fluorescein isothiocyanate; FSC-A: Forward Scatter Area; GC: Guanine-cytosine; GPI: Glycosylphosphatidylinositol; His-tag: Histidine tag; HRP: Horseradish peroxidase; IM: Inner membrane; IPTG: Isopropyl $\beta$-d-1-thiogalactopyranoside; INP: Ice 
nucleation protein; LB: Luria Bertani; Lgt: Diacylglyceryl transferase; Lnt: N-acyltransferase; Lol: Localisation of lipoprotein; Lpp: Braun's lipoprotein; LspA: Signal peptidase II; M.W.: Molecular weight; MBP: Maltose binding protein; MES: 2-(N-morpholino) ethanesulfonic acid; OD: Optical density; OM: Outer membrane; OmpA: Outer membrane protein A; OMPs: Outer membrane proteins; OPH: Organophosphorus hydrolase; PBS: Phosphate-buffered saline; PIPE: Polymerase incomplete primer extension; PMSF: Phenylmethhylsulfonyl fluoride; RT: Room temperature; SDS-PAGE: Sodium dodecyl sulfate Polyacrylamide gel electrophoresis; SSC-A: Side Scatter Area; SSC-W: Side Scatter Width; TAM: Translocation and Assembly Module; T5SS: Type V secretion system; TEM: Transmission electron microscope; TEV: Tobacco etch virus.

\section{Acknowledgements}

We would like to acknowledge Prof Anna Rita Taddei for the image of Postembedded TEM. Simona Tavarini is acknowledged for her support with the FACS analysis.

\section{Author contributions}

ID and CB designed and conceived the study; SN performed the major part of the experimental work; SN, CLG and CB wrote the manuscript; MG and LP contributed to the experimental work; FG performed all the electron microscopy analysis; ID and DM critically revised the manuscript. All authors have read and approved the manuscript.

\section{Availability of data and materials}

The datasets used and analysed during the current study are available from the corresponding author.

\section{Ethics approval and consent to participate}

Not applicable.

\section{Consent for publication}

Not applicable.

\section{Competing interests}

This work was sponsored by GlaxoSmithKline Biologicals SA. All authors have declared the following interests: $M G, F G, L P, I D, D M$ and $C B$ are employees of the GSK group of companies. CLG is a consultant for GSK, Italy. SN is a PhD student (University of Bologna) at GSK, Italy.

\section{Author details}

${ }^{1}$ GSK, via Fiorentina 1, 53100 Siena, Italy. ${ }^{2}$ Department of Pharmacy and Biotechnology (FaBiT), University of Bologna, Bologna, Italy.

Received: 29 September 2020 Accepted: 23 January 2021

Published online: 02 February 2021

\section{References}

1. Gal I, Schlesinger O, Amir L, Alfonta L. Yeast surface display of dehydrogenases in microbial fuel-cells. Bioelectrochemistry. 2016;112:53-60. https:// doi.org/10.1016/j.bioelechem.2016.07.006.

2. Mathew E, Zhu H, Connelly SM, Sullivan MA, Brewer MG, Piepenbrink MS, et al. Display of the HIV envelope protein at the yeast cell surface for immunogen development. PLOS ONE. 2018;13(10):e0205756.

3. Shang Y, Tesar D, Hötzel I. Modular protein expression by RNA transsplicing enables flexible expression of antibody formats in mammalian cells from a dual-host phage display vector. Protein Eng Des Sel. 2015;28:437-44.

4. Parola C, Mason DM, Zingg A, Neumeier D, Reddy ST. Genome engineering of hybridomas to generate stable cell lines for antibody expression. Methods Mol. Biol. 2018

5. Nika L, Wallner J, Palmberger D, Koczka K, Vorauer-Uhl K, Grabherr R. Expression of full-length HER2 protein in Sf9 insect cells and its presentation on the surface of budded virus-like particles. Protein Expr Purif. 2017;136:27-38. https://doi.org/10.1016/j.pep.2017.06.005.

6. Tasumi S, Kobayashi K, Takanashi S, Asakawa S, Nakamura O, Kikuchi K et al. Expression and presentation of immune-related membrane proteins of fish by a cell surface display platform using insect cells. Mol Immunol. 2019;1 14:553-60. https://doi.org/10.1016/j.molimm.2019.07.020.
7. Löfblom J, Rosenstein R, Nguyen MT, Ståhl S, Götz F. Staphylococcus carnosus: from starter culture to protein engineering platform. Appl Microbiol Biotechnol. 2017;101:8293-307.

8. Michon C, Langella P, Eijsink VGH, Mathiesen G, Chatel JM. Display of recombinant proteins at the surface of lactic acid bacteria: Strategies and applications. Microb Cell Fact BioMed Central. 2016;15:1-16.

9. Salema V, Fernández LÁ. Escherichia coli surface display for the selection of nanobodies. Microb Biotechnol. 2017;10:1468-84.

10. Wernérus H, Ståhl S. Biotechnological applications for surface-engineered bacteria. Biotechnol Appl Biochem. 2004;40:209.

11. Lee SY, Choi JH, Xu Z, Smith GP, Li M, Lee J-S, et al. Microbial cell-surface display. Trends Biotechnol. 2003;21:45-52.

12. Blount ZD. The unexhausted potential of E. coli. Elife. 2015;4:1-12.

13. van Bloois E, Winter RT, Kolmar H, Fraaije MW. Decorating microbes: Surface display of proteins on Escherichia coli. Trends Biotechnol. 2011;29:7986. https://doi.org/10.1016/j.tibtech.2010.11.003.

14. Nhan NT, de Valdivia EG, Gustavsson M, Hai TN, Larsson G. Surface display of Salmonella epitopes in Escherichia coli and Staphylococcus carnosus. Microb Cell Fact. 2011;10:1-8.

15. Jarmander J, Gustavsson M, Do TH, Samuelson P, Larsson G. A dual tag system for facilitated detection of surface expressed proteins in Escherichia coli. Microb Cell Fact. 2012;11:1-10.

16. Gustavsson M, Do T-H, Lüthje P, Tran NT, Brauner A, Samuelson P, et al. Improved cell surface display of Salmonella enterica serovar Enteritidis antigens in Escherichia coli. Microb Cell Fact. 2015;14:47.

17. Jo JH, Han CW, Kim SH, Kwon HJ, Lee HH. Surface display expression of Bacillus licheniformis lipase in Escherichia coli using Lpp'OmpA chimera. J Microbiol. 2014;52:856-62.

18. Earhart CF. Use of an Lpp-OmpA fusion vehicle for bacterial surface display. Methods Enzymol. 2000;326:506-16.

19. Fasehee H, Rostami A, Ramezani F, Ahmadian G. Engineering E coli cell surface in order to develop a one-step purification method for recombinant proteins. AMB Express. 2018. https://doi.org/10.1186/s1356 8-018-0638-8

20. DelPrete S, Perfetto R, Rossi M, Alasmary FAS, Osman SM, AlOthman Z, et al. A one-step procedure for immobilising the thermostable carbonic anhydrase (SspCA) on the surface membrane of Escherichia coli. J Enzyme Inhib Med. 2017;32:1 120-8. https://doi.org/10.1080/14756 366.2017.1355794.

21. Zhang Z, Tang R, Bian L, Mei M, Li C, Ma X, et al. Surface immobilization of human Arginase-1 with an engineered ice nucleation protein display system in E. Coli. PLoS ONE. 2016;11:1-13.

22. Kim D, Ku S. Bacillus cellulase molecular cloning, expression, and surface display on the outer membrane of Escherichia coli. Molecules. 2018;23:503.

23. Wells TJ, Totsika M, Schembri MA. Autotransporters of Escherichia coli: a sequence-based characterization. Microbiology. 2010;156:2459-69.

24. Nishimura K, Tajima N, Yoon YH, Park SY, Tame JRH. Autotransporter passenger proteins: virulence factors with common structural themes. J Mol Med. 2010;88:451-8.

25. Bernstein HD, Branch B. Protein secretion by the autotransporter pathway. Mol Microbiol. 2019;97:205-15.

26. Leo CJ, Linke D. A unified model for BAM function that takes into account type $\mathrm{Vc}$ secretion and species differences in BAM composition. AIMS Microbiol. 2018;4:455-68.

27. Albenne C, leva R. Job contenders: roles of the $\beta$-barrel assembly machinery and the translocation and assembly module in autotransporter secretion. Mol Microbiol. 2017;106:505-17.

28. Jose J. Autodisplay: efficient bacterial surface display of recombinant proteins. Appl Microbiol Biotechnol. 2006;69:607-14.

29. Francisco JA, Georgiou G. The expression of recombinant proteins on the external surface of Escherichia coli biotechnological applications. Ann NY Acad Sci. 1994;745:372-82.

30. Narita SI, Tokuda H. Bacterial lipoproteins; biogenesis, sorting and quality control. Biochim Biophys Acta Mol Cell Biol Lipids. 2017;1862:1414-23. https://doi.org/10.1016/j.bbalip.2016.11.009.

31. Zückert WR. Secretion of bacterial lipoproteins: through the cytoplasmic membrane, the periplasm and beyond. Biochim Biophys Acta Mol Cell. 2014;1843:1509-16. https://doi.org/10.1016/j.bbamcr.2014.04.022.

32. Okuda S, Tokuda H. Lipoprotein sorting in bacteria. Annu Rev Microbiol. 2011;65:239-59. https://doi.org/10.1146/annurev-micro-090110-102859. 
33. Leyton DL, Belousoff MJ, Lithgow T. The BAM Complex 2015;1329. https:// doi.org/10.1007/978-1-4939-2871-2

34. Kawahara $\mathrm{H}$. The structures and functions of ice crystal-controlling proteins from bacteria. J Biosci Bioeng. 2002;94:492-6.

35. Li Q, Yan Q, Chen J, He Y, Wang J, Zhang H, et al. Molecular characterization of an ice nucleation protein variant (InaQ) from Pseudomonas syringae and the analysis of its transmembrane transport activity in Escherichia coli. Int J Biol Sci. 2012;8:1097-108.

36. Kovacs-Simon A, Titball RW, Michell SL. Lipoproteins of bacterial pathogens. Infect Immun. 2011;79:548-61.

37. Braun V, Hantke K. Lipoproteins: structure, function, biosynthesis. Subcell Biochem. 2019. https://doi.org/10.1007/978-3-030-18768-2_3.

38. Bonsor DA, Grishkovskaya I, Dodson EJ, Kleanthous C. Molecular mimicry enables competitive recruitment by a natively disordered protein. J Am Chem Soc. 2007;129:4800-7.

39. Simpson BW, May JM, Sherman DJ, Kahne D, Ruiz N. Lipopolysaccharide transport to the cell surface: biosynthesis and extraction from the inner membrane. Philos Trans R Soc B Biol Sci. 2015;370:20150029. https://doi. org/10.1098/rstb.2015.0029

40. Tsukahara J, Mukaiyama K, Okuda S, Narita SI, Tokuda H. Dissection of LolB function - Lipoprotein binding, membrane targeting and incorporation of lipoproteins into lipid bilayers. FEBS J. 2009;276:4496-504.

41. García-Pastor L, Puerta-Fernández E, Casadesús J. Bistability and phase variation in Salmonella enterica. Biochim Biophys Acta Gene Regul. 2019;1862:752-8

42. Mergulhão FJM, Summers DK, Monteiro GA. Recombinant protein secretion in Escherichia coli. Biotechnol Adv. 2005:23:177-202.

43. Freudl R. Signal peptides for recombinant protein secretion in bacterial expression systems. Microb Cell Fact. 2018;17:1-10. https://doi. org/10.1186/s12934-018-0901-3.

44. Endres RG. Bistability: requirements on cell-volume, protein diffusion, and thermodynamics. PLOS ONE. 2015;10:1-22.

45. Fantappiè L, Irene C, De Santis M, Armini A, Gagliardi A, Tomasi M, et al. Some gram-negative lipoproteins keep their surface topology when transplanted from one species to another and deliver foreign polypeptides to the bacterial surface. Mol Cell Proteomics. 2017;16:1348-64. https ://doi.org/10.1074/mcp.M116.065094.

46. Karami A, Latifi AM, Khodi S. Comparison of the organophosphorus hydrolase surface display using InaVN and Lpp-OmpA systems in Escherichia coli. J Microbiol Biotechnol. 2014:24:379-85.

47. Shimazu M, Mulchandani A, Chen W. Cell surface display of organophosphorus hydrolase using ice nucleation protein. Biotechnol Prog. 2001;17:76-80.
48. Hooda Y, Shin HE, Bateman TJ, Moraes TF. Neisserial surface lipoproteins: Structure, function and biogenesis. Pathog Dis. 2017;75:1-14.

49. Hooda Y, Lai CCL, Judd A, Buckwalter CM, Shin HE, Gray-Owen SD, et al. Slam is an outer membrane protein that is required for the surface display of lipidated virulence factors in Neisseria. Nat Microbiol. 2016;1:16009. https://doi.org/10.1038/nmicrobiol.2016.9.

50. Konar M, Rossi R, Walter H, Pajon R, Beernink PT. A mutant library approach to identify improved meningococcal factor $\mathrm{H}$ binding protein vaccine antigens. PLoS ONE. 2015;10:1-17.

51. Simmons LC, Yansura DG. Translational level is a critical factor for the secretion of heterologous proteins in Escherichia coli. Nat Biotechnol. 1996;14:629-34.

52. Arnold DL, Preston GM. Pseudomonas syringae: Enterprising epiphyte and stealthy parasite. Microbiol (United Kingdom). 2019;165:251-3.

53. Schmid D, Pridmore D, Capitani G, Battistutta R, Neeser JR, Jann A. Molecular organisation of the ice nucleation protein InaV from Pseudomonas syringae. FEBS Lett. 1997;414:590-4. https://doi.org/10.1016/ S0014-5793(97)01079-X

54. Bao S, Yu S, Guo X, Zhang F, Sun Y, Tan L, et al. Construction of a cellsurface display system based on the $\mathrm{N}$-terminal domain of ice nucleation protein and its application in identification of mycoplasma adhesion proteins. J Appl Microbiol. 2015;119:236-44.

55. Li L, Kang DG, Cha HJ. Functional display of foreign protein on surface of Escherichia coli using N-terminal domain of ice nucleation protein. Biotechnol Bioeng. 2004;85:214-21.

56. Bae W, Mulchandani A, Chen W. Cell surface display of synthetic phytochelatins using ice nucleation protein for enhanced heavy metal bioaccumulation. J Inorg Biochem. 2002;88:223-7.

57. Hörnström D, Larsson G, van Maris AJA, Gustavsson M. Molecular optimization of autotransporter-based tyrosinase surface display. Biochim Biophys Acta Biomembr Elsevier. 2019:1861:486-94.

58. Klock HE, Koesema EJ, Knuth MW, Lesley SA. Combining the polymerase incomplete primer extension method for cloning and mutagenesis with microscreening to accelerate structural genomics eforts. Proteins Struct Funct Genet. 2008:71:982-94.

59. Stevenson J, Krycer JR, Phan L, Brown AJ. A practical comparison of ligation-independent cloning techniques. PLoS ONE. 2013;8:8-14.

\section{Publisher's Note}

Springer Nature remains neutral with regard to jurisdictional claims in published maps and institutional affiliations.
Ready to submit your research? Choose BMC and benefit from:

- fast, convenient online submission

- thorough peer review by experienced researchers in your field

- rapid publication on acceptance

- support for research data, including large and complex data types

- gold Open Access which fosters wider collaboration and increased citations

- maximum visibility for your research: over $100 \mathrm{M}$ website views per year

At BMC, research is always in progress.

Learn more biomedcentral.com/submissions 